\title{
O cuidado com o corpo como estratégia de sujeitos generificados
}

Resumo: O artigo é parte de uma dissertação de mestrado que discutiu alguns dos modos pelos quais jovens mulheres significam, apre(e)ndem e vivenciam, contemporaneamente, o cuidado com o corpo. Inscreve-se no campo dos Estudos de Gênero nas vertentes que propõem aproximações críticas com a perspectiva pós-estruturalista de Michel Foucault. Utiliza a abordagem metodológica da análise de discurso para examinar discussões travadas por alunas de uma escola pública no RS. Das análises que resultalram deste corpus de investigação, focaliza-se, aqui, um movimento que permite pensar os cuidados com o corpo como uma estratégia potente na produção de corpos generificados.

Palavras-chave: Imagem corporal. Identidade de gênero. Adolescente. Ensino fundamental e médio.

\section{INTRODUÇÃO}

Este artigo é parte de uma dissertação ${ }^{1}$ em que se discutem alguns dos modos pelos quais jovens mulheres significam, apre(e)ndem e vivenciam, contemporaneamente, o cuidado com o corpo. Tomando como referência os estudos de gênero e os estudos culturais, especificamente aquelas vertentes que têm proposto uma aproximação crítica com a perspectiva pós-estruturalista de Michel Foucault, examino 'textos' que resultaram de discussões realizadas com 18 jovens entre 13 e 15 anos, alunas da $8^{\mathrm{a}}$ série do ensino fundamental e do $1^{\circ}$ ano do ensino médio do Colégio de Aplicação

"Mestre em Educação (PPGEDU - UFRGS), Professor Adjunto do Curso de Educação Física da ULBRA - CANOAS/RS. E-mail: zdamico@yahoo.com.br

1 DAMICO, José. Quantas calorias eu preciso [gastar] para emagrecer com saúde? Como mulheres jovens aprendem estratégias para cuidar do corpo. 2005. Programa de PósGraduação em Educação da UFRGS. Linha de Pesquisa Educação, sexualidade e relaçõe de gênero. Orientadora: Dagmar Estermann Meyer; Co-orientadora: Dora L. de Oliveira. 


\section{Ensaios}

da Universidade Federal do Rio Grande do Sul (CAP/UFRGS). Essas discussões foram conduzidas em seis reuniões de dois grupos focais, realizadas em 2004, as quais foram gravadas e, posteriormente, transcritas para análise. As falas das jovens foram exploradas tomando como base os conceitos de cultura, discurso, gênero e poder, com o propósito de problematizar os diferentes modos pelos quais o cuidado com o corpo é significado, apre(e)ndido e vivido nesse contexto.

Neste artigo, focalizo particularmente um movimento que permite re-conhecer e re-significar os cuidados com o corpo como uma estratégia intimamente implicada na produção de corpos genereficados na contemporaneidade. Argumento que o corpo, já tematizado como território de inscrição de identidades, passa a funcionar como operador de sistemas de classificação e hierarquização social, na medida em que atributos como a forma física e a aparência que revelam são elevados a critérios que posicionam e valoram, diferentemente, estilos de vida e sujeitos na cultura contemporânea. Para tanto, começo por situar, brevemente, alguns pressupostos e conceitos do referencial teórico-metodológico que sustenta a discussão aqui realizada. Em seguida, apresento e discuto diferentes práticas de cuidado corporal que as jovens mulheres participantes realizam, para, então, apontar algumas das contribuições de um estudo com esse enfoque para a compreensão de relações que se estabelecem entre cultura, corpo e juventude nestes tempos em que nos movimentamos.

\section{SITUANDO A TEMÁTICA}

Para iniciar, quero me deter um pouco mais sobre a questão do cuidado, que é central para a seqüência deste estudo. A escolha pela expressão "cuidado" se justifica na medida em que abrange uma série de dimensões afetivas e cognitivas dos indivíduos - o cuidar pode designar uma ação voltada tanto para o próprio sujeito como para o outro. No primeiro movimento, trata-se do cuidar de si no sentido de uma reflexão e uma ação sobre si mesmo; no segundo, o pensamento e o agir se voltam para o outro, sendo que

Movimento, Porto Alegre, v.13, n. 01, p.93-117, janeiro/abril de 2007. 
algumas correntes filosóficas (como o positivismo) concebem o cuidar em relação ao outro como uma atitude altruísta, abnegada e desinteressada.

A argumentação que proponho, articulada ao campo dos estudos feministas, visa considerar o cuidado como prática histórica e cultural, evitando modelos explicativos e naturalizantes. $\mathrm{O}$ cuidado com o corpo, objetivado em um conjunto de práticas corporais que vão desde as escolhas das dietas, das roupas e da aparência como um todo, configura-se como um estilo, um jeito de ser aprendido e reaprendido de diferentes modos durante toda a vida. Concorrem para isso o alargamento das possibilidades tecnológicas, os dietéticos, os moderadores de apetite, os exercícios físicos e as cirurgias com fins estéticos. Outro fator que contribui para o cuidado com o corpo é a proliferação de imagens e discursos sobre a beleza corporal e cotidiano sexual e alimentar, articulados a uma preocupação cada vez mais freqüente com a saúde, associada ao bem-estar corporal. As instâncias dessas aprendizagens podem ser variadas, como as artes femininas - passadas de geração em geração -, os ensinamentos no âmbito familiar, as conversas e críticas com amigas da escola, a busca do amor romântico, as diferentes matérias na escola, a publicidade e a mídia em geral.

Como apontam diferentes estudos e autores/as (SANT'ANNA, 2001, FRAGA, 2002; SILVA, A., 2001), vivemos um tempo em que meios de comunicação de massa, como revistas, jornais e programas de televisão, produzem e veiculam toda uma discursividade sobre e para o corpo, contemplando, dentre outras coisas, modos de vestir, comer, exercitar-se, maquiar-se ou divertir-se. Todas essas práticas corporais constituem um conjunto de relações de saber-poder que produzem nossas múltiplas formas de ser e de estar no mundo.

Essa visibilidade que o espaço social empresta ao corpo não é nova, mas ela parece traduzir-se como um imperativo cada vez mais exigente, principalmente em relação às mulheres - e às mulheres jovens, em especial -, justificando as intervenções que

Movimento, Porto Alegre, v.13, n. 01, p.93-117, janeiro/abril de 2007. 
devem ou podem ser realizadas para a aquisição e/ou manutenção de um corpo jovem para as mulheres adultas ou, ainda, para que corpos de crianças se tornem rapidamente jovens e atraentes, e tudo isso torna necessários investimentos massivos no corpo.

No contexto dessa visibilidade, é possível perceber que as mulheres jovens têm sido posicionadas como personagens centrais desses investimentos, hoje genericamente definidos como "culto ao corpo'. Tal posição tem sido demarcada com argumentos que descrevem as jovens (e a relação que estas estabelecem com seus corpos) como belas e sedutoras e, ao mesmo tempo, irresponsáveis, emocionalmente problemáticas e personagens principais de condutas e situações 'de risco', tais como gravidez precoce, doenças sexualmente transmissíveis, uso de drogas, desordens alimentares e sedentarismo.

Esse estatuto de ameaça a si mesmas e aos outros, atribuído às mulheres jovens, evidenciado por muitos discursos médicos, psicológicos e educacionais, parece fazer eco aos discursos que colocam a 'adolescência' como uma etapa da vida vivida do mesmo modo por todos os jovens, que seria 'naturalmente' conturbada e que se caracterizaria pela contestação em relação às demandas das gerações mais velhas, dentre outras apreciações.

No âmbito dessa discursividade, práticas contemporâneas de modelagem e modificação dos corpos assumem centralidade. Miriam Adelman (2003), com base em um estudo da historiadora norte-americana Joan Brumberg (1997), que analisou cem anos de diários de jovens mulheres, argumenta, em relação a isso, que:

As meninas de outras épocas escreviam principalmente sobre os desafios do amadurecimento do caráter; hoje em dia, a preocupação central gira em torno da aparência física e da apresentação do corpo para os outros. Para essas meninas, a autoestima parece depender muito mais do tamanho do nariz, da cintura ou das pernas do que da maneira que desenvolvem capacidades de relacionamento com o mundo (ADELMAN, 2003, p.451).

Mavimento, Porto Alegre, v.13, n. 01, p.93-117, janeiro/abril de 2007. 
Nesses processos que investem sobre o corpo jovem, noções sobre saúde, bem-estar, alimentação adequada e beleza são constantemente renovadas e rearticuladas, instituindo formas de cuidado com significações distintas de prazer, de contenção, de resistência, de feminilidade e de masculinidade. Determinadas práticas corporais passam a ser objeto de uma atenção constante a partir da qual se aposta, por exemplo, que o cuidado com uma alimentação tida como equilibrada resultaria em uma aparência mais "saudável" e que exercícios físicos orientados seriam determinantes para uma "saúde perfeita".

É nesse sentido que assumo o pressuposto de que o corpo é um "construto sócio-cultural e lingüístico, produto e efeito das relações de poder" (MEYER et al., 2003, p.26) e, a partir dele, rejeitamos, em nossa análise, noções essencialistas e universais de corpo e de gênero, para apostar na multiplicidade e na conflitualidade dos processos pelos quais a cultura constrói e distingue corpos e sujeitos masculinos e femininos, inscrevendo-os, também, em diferentes etapas do ciclo vital.

É com esse olhar que discuto, aqui, determinadas práticas corporais que as jovens desenvolvem para cuidar do corpo, entendendo-as como práticas informadas por, e sintonizadas com, regras de normalidade socialmente instituídas e legitimadas, no interior das quais o corpo emerge como território e, ao mesmo tempo, como um potente operador de diferenciações.

Assim, ao operar metodologicamente com a análise de discurso de "inspiração foucaultiana", busquei trabalhar as falas, decompôlas, multiplicar os sentidos que elas podem conter, bem como localizar os rastros ou as marcas dos discursos que se articulam para torná-las possíveis.

\section{OLHARES SOBRE A APARÊNCIA}

Interessa-me aqui explorar as falas produzidas pelas jovens nas discussões grupais, privilegiando práticas de cuidado que reúnem diferentes saberes com os quais as jovens se relacionam para produzirem mudanças no corpo.

Movimento, Porto Alegre, v.13, n. 01, p.93-117, janeiro/abril de 2007. 


\section{Ensaios}

Para tanto, considero práticas de cuidado aquelas em que se produz ou se transforma a experiência de si. Nesse sentido, tais práticas materializam-se na relação com o "outro". Esse outro pode ser um conselho do/da professor/a, as conversas com os/as colegas da escola, um programa de televisão, as revistas voltadas para jovens ou, ainda, uma conversa com a mãe, por exemplo. É nesse sentido que uma série de práticas, produtos e espaços culturais que são educativas, e é nelas que o poder se localiza e se exercita (STEINBERG, 1997).

Deste modo, analisar as práticas pedagógicas que constituem as jovens, enquanto operações concretas de relação consigo mesmas, significa investigar as formas de produção de sujeitos jovens em nossa cultura. Trata-se, ainda, de um modo de ser estimulado e ensinado por diferentes elementos que mobilizam e limitam o indivíduo, que produz adesões e resistências.

\section{AS DÚVIDAS QUE PESAM}

As escolhas das jovens parecem obedecer à dinâmica de poder descrita por Foucault (2002) de ocupar alternadamente um lugar ou outro do poder. Elas realizam gestos de sucumbir aos discursos de controle para, logo em seguida, resistir, deslocar-se. Ao abordar quais eram as principais dúvidas que as jovens participantes do grupo tinham em relação aos cuidados com o corpo:

Betina: Quantas calorias eu preciso para emagrecer com saúde? Porque eu não vou comer, porque daí eu vou engordar, daí a minha mãe me diz assim: "não, Betina, tu não precisas fazer regime, tu não engordas comendo 2.000 calorias". Depende da massa corporal de cada pessoa. Eu tenho que ver qual é a minha faixa de calorias, porque, se eu comer, não vai dar em nada.

Ao perguntar-se sobre quantas calorias precisa para poder emagrecer e manter a saúde, Betina está salientando que as informações de que dispõe são confusas. Ou seja, ela questiona a informação corrente de que magreza poderia corresponder à saúde, questionando também os conselhos da mãe sobre a quantidade

Mavimento, Porto Alegre, v.13, n. 01, p.93-117, janeiro/abril de 2007. 
de calorias, a partir da relação que estabelece entre calorias e massa corporal.

Ao levantar essas dúvidas, a jovem põe em cheque uma série de informações que têm forte expressão no campo biomédico, principalmente aquelas informações relacionadas ao sobrepeso. Além dessas, também são questionadas, por exemplo, as que enfatizam a possibilidade de prevenção de doenças por meio de regimes de emagrecimento e exercícios físicos regulares.

Trata-se aqui de compreender como certos mecanismos de diferenciação de gênero são produzidos. As restrições ao apetite feminino não se referem somente à ingestão dos alimentos, mas a um controle social da fome feminina, o que não quer dizer que os homens não venham também sendo alvos de discursos que condenam a fome exagerada ou a obesidade, mas certamente as mulheres são muito mais vigiadas do que eles.

Atualmente, dois importantes mercados concorrem para angariar consumidores/as vorazes para suas causas. Trata-se das potentes indústrias farmacêutica e dietética, que pretendem definir a aparência física "correta" e tentam fazê-lo difundindo que tal aparência está ao alcance de todos.

O que se trata aqui é de analisar a interferência das relações de poder num processo em que se instituem condutas e conhecimentos. A operação realizada por vários campos de conhecimento em relação à aquisição de um determinado corpo magro pode ser caracterizada por uma reserva cognitiva, do ponto de vista de disciplinar, condicionando o indivíduo para que realize as propostas de mudanças no seu comportamento, mesmo que seja por pouco tempo.

Esses conhecimentos apresentados através do discurso do senso comum correspondem aos saberes produzidos pela ciência biomédica, que produz fórmulas e medidas em relação ao corpo que deveriam ser aceitas como padrão por todas as pessoas. As tecnologias biomédicas pesquisam e propõem aos indivíduos que há mecanismos tecnológicos para se regrar a forma do corpo (SILVA, A., 2001).

Movimento, Porto Alegre, v.13, n. 01, p.93-117, janeiro/abril de 2007. 


\section{Ensaios}

Em relação à forma, à composição do corpo e a sua performance, Ana Márcia Silva destaca a especialização de uma área médica, a Medicina do Esporte, que, segundo a autora,

[...] tem atuado numa perspectiva normativa para homens e mulheres de determinadas faixas etárias e em três compleições físicas. Atua no âmbito da análise da composição corporal, determinando equações e correlações ideais, elaboradas a partir de estatísticas (SILVA. A, 2001, p.19).

Nessa direção, o argumento da autora permite tratar o corpo como um território privilegiado para a atuação de mecanismos de normalização (SILVA, 1997). Nas palavras de François Ewald, a norma seria:

[...] Uma maneira de um grupo se dotar de uma medida comum segundo um rigoroso princípio de auto-referência, sem recurso a nenhuma exterioridade, quer seja a de uma idéia quer a de um objeto.

$\mathrm{O}$ procedimento normativo pode obedecer a diferentes esquemas: esquema panóptico das disciplinas, esquema probabilista das seguranças, esquema comunicacional da norma técnica (EWALD, 1993, p.108).

A norma inscreve-se em uma positividade justamente pela transformação que ela possibilita nas disciplinas, quer dizer, a passagem de disciplinas que bloqueiam para disciplinas engrenagens. Quando denominamos um comportamento de anormal, acreditamos que podemos mudar e nos obrigamos a transformá-lo (EWALD, 1993).

$\mathrm{Na}$ tentativa de compreender os regimes de emagrecimento a partir dos instrumentos disciplinares, pode-se dizer que a busca pela esbelteza congrega, contemporaneamente, um número cada vez maior de pessoas, e isso implica a necessidade de desenvolver mais o autocontrole para resistir ao prazer de comer, ao mesmo tempo em que se aumenta a responsabilidade e a culpa quando esse prazer é proporcionado.

Se, no nível disciplinar, a norma funciona a partir de um esquema arquitetural de espaços onde o indivíduo pode fazer um Movimento, Porto Alegre, v.13, n. 01, p.93-117, janeiro/abril de 2007. 
juízo de si próprio, no nível da segurança, a norma vai funcionar como gestora para as populações. Trata-se do acesso à transformação do funcionamento das relações de poder, de uma microfísica do poder para uma dimensão bio-política.

Para serem resolvidos, os problemas de organização e de regulação da sociedade e dos indivíduos dependem de uma certa racionalidade de decompor, recompor e ordenar alguns dados de realidade, enfim, de uma prática que formaliza o cálculo das probabilidades. O cálculo das probabilidades é a prática fundamental da constituição da segurança social; a sociedade, por intermédio de dados quantificados, analisaria seus problemas em função dos possíveis riscos verificados (EWALD, 1993).

A mudança que se efetivou nas normas técnicas deveu-se à descoberta de que havia regularidade no desvio de comportamento e, principalmente, havia problemas na avaliação do risco por parte de cada indivíduo. A descoberta referida decorre dos estudos estatísticos, os quais constataram que havia regularidade nos desvios de comportamento, ou seja, onde impera a vida desregrada, também há regularidade.

A mídia e a medicina, baseadas na estatística, têm divulgado avaliações que vinculam doenças crônico-degenerativas; o câncer de pulmão ao fumo, a obesidade à solidão, ou, ainda, o sedentarismo à doenças cardíacas. Essas doenças teriam em comum o fato de serem "causadas" pelo gerenciamento equivocado das escolhas em relação ao futuro. Essa operação efetuada pela estatística e apropriada pela mídia e pela medicina pode produzir sentimentos de culpa. É possível que os indivíduos problematizem sua solidão e/ou falta de exercícios, por exemplo, a partir do risco de adquirir doenças.

$O$ fator de fundamental importância para que esse mecanismo de poder se exerça sobre a população está na sua positividade, que se apóia na racionalidade econômica e nos saberes estatísticos. Em outras palavras, o modo como a sociedade ou o Estado incumbem-se da vida, como a organizam e compensam possíveis eventualidades e delimitam suas chances e possibilidades biológicas (FOUCAULT, 2002).

Movimento, Porto Alegre, v.13, n. 01, p.93-117, janeiro/abril de 2007. 
As análises que venho apresentando ilustram que a busca da maioria das mulheres por um corpo cada vez mais magro configura-se como uma das mais potentes relações de poder-saber da contemporaneidade. A base discursiva foi se ampliando, desde os discursos com relação à urbanização e ao sedentarismo nas sociedades que caminhavam para a industrialização no século XIX, os quais demandariam a promoção de uma alimentação saudável e de uma atividade corporal em benefício da saúde, até os discursos "científicos", que não cessaram, até os dias de hoje, de formular propostas de intervenção, desde dietas alimentares e de sono, até roupas, cosméticos, atividades corporais, lazer, sexo e muitas outras. Sobre essa matriz formativa e, por vezes, em contraposição, desenvolveu-se um movimento social e econômico que conduziu a um estilo de construir e operar com o corpo.

Neste sentido, há um esforço na atualidade, por tolerar as diferenças de comportamento dos indivíduos, mesmo aquelas práticas corporais consideradas anormais. No entanto, o controle sobre essas práticas aumentou. No caso das participantes da pesquisa, elas relataram que muitas vezes se sentem constrangidas quando algum/a professor/a chega no bar da escola e reclama de suas escolhas alimentares. Deste modo, o lugar escola funciona como um espaço de controle sobre suas condutas.

Para as jovens participantes, muitas das dúvidas que têm em relação ao seu corpo podem ser resolvidas na escola. Pergunteilhes como isso ocorre, e algumas jovens responderam assim:

Denise: Eu aprendi bastante no colégio. Sempre, na educação física, a gente pergunta quando tem alguma dúvida sobre o corpo e como se cuidar. Eu pergunto [sobre] comer coisas saudáveis, fazer exercício físico, essas coisas assim.

Janaína: Às vezes, eu fico uma semana antes de uma festa fazendo a dieta dos líquidos, mas não é nada demais, foi a minha professora de ginástica quem me ensinou.

Silvia: Quando eu tinha uns 11/12 anos, eu não me preocupava nada, eu comia um monte. Daí,

Movimento, Porto Alegre, v.13, n. 01, p.93-117, janeiro/abril de 2007. 
depois, eu comecei a me preocupar mais. No ano passado, eu fiz uma dieta, só que eu nem estava gorda nem nada. Eu comecei a ler nas revistas e achei legal. Eu estava jogando vôlei, e o professor também, às vezes, dava uns conselhos para emagrecer. Aí, depois, eu larguei tudo e só comia, comia, comia um monte. Depois, eu voltava, fazia dieta e parava de novo.

A escola e as academias, para as jovens, configuram-se como um espaço importante de aprendizagem sobre o corpo. Para Denise, o espaço da aula de educação física funciona como um lugar de aprendizado que não se restringe ao conteúdo escolar.

Nas aulas de educação física, não importando se na educação superior ou na educação básica, está presente, de modo bastante explícito, a constituição de identidades ${ }^{2}$ hegemônicas, tanto no que se refere ao gênero, quanto à raça/etnia ou sexualidade (LOURO, 1997). Isso se dá através de discursos que constituem as várias disciplinas, como a biologia, vinculada à idéia da manutenção da saúde e da higiene, a psicologia, voltada para o desempenho de habilidades, em que o autocontrole e a força mental são importantes componentes da participação esportiva, ou, ainda, pela influência militarista na formação histórica da educação física e do esporte no Brasil - da qual posso destacar uma série de normas morais de condutas e controle dos corpos.

Nas atividades de educação física, o controle dos corpos materializa-se nas estratégias de separação de grupos, nos exercícios e jogos formativos, nas escolhas dos desportos e dos/das participantes, o que permite o acesso do professor ou professora aos corpos dos/as alunos/as, tornando visíveis suas atitudes e comportamentos e, conseqüentemente, permitindo que sejam constantemente examinados na busca por uma intervenção eficiente no processo de formação dos sujeitos (LOURO, 1997).

${ }^{2}$ Utilizo o conceito de identidade aqui como "o conjunto de características que distinguem os diferentes grupos sociais e culturais entre si [...] a identidade cultural só pode ser entendida em conexão com a diferença, concebida como um processo social e discursivo" (SILVA, 2000, p.69).

Movimento, Porto Alegre, v.13, n. 01, p.93-117, janeiro/abril de 2007. 
No segundo fragmento, Janaína diz que tem utilizado uma dieta aprendida com sua professora de ginástica. É interessante perceber que a jovem emprega a dieta líquida em uma situação muito específica, ou seja, para um evento em que necessita mostrar mais o seu corpo. As dietas líquidas, que eram utilizadas originalmente com objetivos médicos para situações de exame ou após um evento cirúrgico, ganham outras funções na contemporaneidade.

Um outro aspecto que merece ser ressaltado se refere ao modo como determinadas modalidades esportivas, artísticas e ocupacionais empregam o controle do peso como mecanismo de obtenção de desempenho e, conseqüientemente, de resultados. Enquadram-se nisso a dança clássica, a ginástica olímpica, as corridas de cavalo e a ginástica rítmica desportiva. Essas práticas corporais constituíram-se num processo histórico que foi paulatinamente investindo no controle do apetite de seus praticantes. Cada uma dessas modalidades fundamenta tal necessidade em atributos naturalizados como femininos, como graça, equilíbrio, autocontrole e leveza.

O sentido do argumento anterior pode ser mais potencializado no contra-ponto relatado por Miriam Adelman através das entrevistas que realizou com mulheres atletas de outros esportes:

\begin{abstract}
Nunca gostei de basquete. Para a mulher, acho que torna a mulher muito masculina. Se você comparar as jogadoras de basquete com as de vôlei, você vê a diferença no físico. Elas são mais troncudas; tem um jeito diferente - eu não gosto (ADELMAN, 2003, p.457).
\end{abstract}

Nesse depoimento, podemos perceber um certo desprezo pelos esportes considerados masculinos, bem como um esforço em referir a feminilidade de determinados esportes e práticas corporais. $\mathrm{O}$ vôlei e a dança seriam atividades mais adequadas para manutenção da feminilidade.

\title{
5 AS DIFERENÇAS ESPELHADAS ENTRE ELAS E ELES
}

Ao serem questionadas sobre as diferenças entre elas e os guris, algumas jovens participantes manifestaram-se assim:

Movimento, Porto Alegre, v.13, n. 01, p.93-117, janeiro/abril de 2007. 
Ana Paula: Uma outra coisa assim que os guris... É mais simples para eles. O organismo deles é diferente do nosso, então, tipo... Eles fazem um esporte e ficam bonitos, sem celulite.

Kátia: E a gente se mata fazendo exercício, e sempre tem uma lá e outra que não sai!

Ana Paula: Não sei se é porque a gente é mais vaidosa e daí a gente... "ai, encontrei uma aqui". Os guris, é mais fácil, é outro metabolismo, é difícil eles terem estria ou celulite, eu acho. A tendência é mais da mulher... Então, eles se cuidam menos...

É interessante perceber que, na primeira discussão, já era ressaltada uma maior facilidade para os garotos quanto aos modos de eles se vestirem, mesmo que isso demande um certo detalhamento. Nos fragmentos acima, vemos que as jovens se comparam com os garotos, apontando para tal facilidade com base nas diferenças de organismos de homens e mulheres. O esporte, para os garotos, não teria como função aperfeiçoar as formas corporais, mas seria uma atividade prazerosa em si mesma, como se os garotos, mesmo não dando tanta importância para o corpo, tivessem vantagens com seu corpo de "homem".

Para as meninas, os exercícios físicos funcionariam como uma das armas para combater o inimigo invencível, ou seja, a celulite ou a estria - um trabalho árduo que se faz necessário. Uma das jovens utiliza a expressão "se mata fazendo exercício", em que parece não restar dúvidas sobre o esforço empregado. Já Ana Paula expressa dois argumentos: o primeiro é que as mulheres, por serem mais vaidosas, acabam por procurar com mais minúcias as marcas indesejáveis no corpo; o segundo decorre das diferenças do metabolismo feminino e masculino, com as meninas tendo mais dificuldades para obter os resultados de uma pele livre de estrias e celulite.

Com esse tipo de argumentação por parte das jovens, notase o favorecimento da naturalização de aspectos biológicos do organismo que inferiorizam o corpo feminino. De acordo com Santos (1998), a naturalização da inferioridade do corpo feminino foi

Movimento, Porto Alegre, v.13, n. 01, p.93-117, janeiro/abril de 2007. 


\section{Ensaios}

construída ao longo da tradição de pelo menos quatro séculos, por meio de práticas materiais ou não, que têm ensinado modos de ver e especificar o mundo, que não é nem um pouco natural.

A operação de busca do detalhe anatômico para definir as diferenças entre a mulher e o homem não é nova. Ao voltar seu escopo especialmente para as mulheres, a ciência não cessou até os dias de hoje de intervir no corpo, sob a moral da "boa-forma" as marcas indesejáveis e os excessos devem ser combatidos. Atualmente, a ciência e seus especialistas promovem crenças nas quais a "celulite" e as estrias, por exemplo, são problemas que podem e devem ser resolvidos através de rituais de autotransformação.

Ao contrário do corpo masculino, o qual, nas discussões que apresentei anteriormente, é considerado "praticamente pronto", o corpo feminino necessita de atitudes de intensificação das rotinas de cuidados e exercícios para tentar corrigir falhas ou diferenças metabólicas entre os sexos. As marcas de desigualdades entre mulheres e homens, difundidas em muitos discursos tecno-científicos, propõem soluções para diminuir tais diferenças orgânicas.

Isso sugere que o auto-exame, assim como as práticas corporais que podem vir acompanhadas do que for detectado, pode ser visto como um tipo de conjunção entre a feminilidade como restrição à liberdade e a feminilidade como meio de liberdade. Ou seja, o cuidado pode servir, por um lado, para atender as exigências culturais de ser feminina, e, por outro, pode significar um meio de aperfeiçoamento pessoal, escolhido por ela, para agradar a si mesma.

Ainda sobre as diferenças entre os meninos e as meninas, perguntei o que achavam dos garotos que se cuidavam. Algumas expressaram-se assim:

Clara: Mas agora está mudando. Eles estão passando creme, se cuidando, fazendo as unhas até. Antigamente não era assim, agora a coisa evoluiu... Tanto os homens quanto as mulheres... Eu acho que é preconceito mesmo...do tipo "mulher é que faz as unhas... homem vai fazer? Isso é coisa de gay". Por exemplo, a cor rosa... Eu não sei por que alguém põe na cabeça que rosa é de mulher.

Movimento, Porto Alegre, v.13, n. 01, p.93-117, janeiro/abril de 2007. 
Suzana: Só porque é guri. É que foi imposto que o guri não pode se cuidar como a guria. Eles têm que ser desleixados...

As jovens estabelecem duas posições opostas nas discussões acima. A primeira é a de "que as coisas estariam evoluindo", e a outra é a "de que não combina muito por ser uma coisa que geralmente é da mulher". Esse assunto surgiu na discussão em função de uma das garotas ter lembrado que, pouco tempo antes, havia aparecido na escola alguns garotos com as unhas pintadas de preto. No contexto da discussão, a palavra "evolução" remete à idéia de surgimento de algo como resultado do processo que o termo designa. No entanto, conforme Goellner:

[...] o culto ao corpo como hoje vivenciamos, em que pesem as especificidades de cada momento histórico e cada cultura, tem seu início no século XVII e se intensifica no século XIX porque, nesse tempo, o corpo adquire relevância nas relações que se estabelecem entre os indivíduos (GOELLNER, 2003, p.35)

Desde esse período, o ocupar-se de si mesmo ganha legitimidade, e, por conseguinte, a aparência do corpo recebe status de ser o corpo, onde o que está em jogo é uma moral das aparências.

Nesse sentido, a emergência, nos tempos atuais, de toda uma discursividade dirigida também aos homens para que cuidem do seu corpo, não só quanto ao vigor muscular e ao rendimento, como também para conservação e melhoria da aparência, tem suas condições de possibilidades no crescimento da indústria da beleza e da saúde, ligadas a uma série de discursos preocupados com o corpo individual. Toda uma variedade de cosméticos, próteses esportivas, tatuagens, dietas individualizadas, suplementos e complementos alimentares, personal traineer, roupas para melhoria da performance atlética e muitas outras novidades, que não cessam de surgir, necessitavam ser ampliadas para além das mulheres enquanto um segmento consumidor.

O conceito de gênero é relacional. Ele supõe que, para cada forma de feminilidade, se constitui uma forma de masculinidade;

Movimento, Porto Alegre, v.13, n. 01, p.93-117, janeiro/abril de 2007. 


\section{Ensaios}

feminino e masculino dependem um do outro para definir-se, um está contido no outro. Tais formulações do conceito permitiram operar tanto sobre a construção social do feminino como também do masculino. Posso, nessa medida, afirmar que a masculinidade passa a ser percebida como culturalmente e discursivamente construída, variando em diferentes sociedades ou no interior de cada uma em diferentes períodos históricos.

A principal questão que se coloca na análise do diálogo acima transcrito é a de que a masculinidade não é tão natural quanto comumente se demonstra. Conforme João Trevisan (1998), o tornarse homem é reforçado por uma oposição a tudo que possa fazê-lo assemelhar-se ao feminino. $\mathrm{O}$ autor acredita que, ao considerar ameaçador tudo aquilo que difere dele, o sistema masculino hegemônico evidencia a fragilidade de sua organização.

Com relação ao vestuário e à moda, desde muito cedo, meninos e meninas vão sendo diferenciados pelas roupas que lhes são vestidas, ensinando-se, desse modo, a cada sexo o que usar. A cor rosa marca desde móveis até roupas e acessórios de meninas, enquanto que a cor azul emoldura uma bola de futebol ou animais selvagens, numa alusão clara à virilidade dos machos de várias espécies animais. $\mathrm{O}$ gosto e a preocupação com a moda têm de ser demonstrados pelas mulheres; as expressões contrárias, em boa parte das vezes, causam constrangimentos.

Desse ponto de vista, a masculinidade é um gênero minuciosamente vigiado que não permite pequenos desvios. A questão que se coloca aqui é: como, no caso dos grupos de iguais (como os/as jovens escolares), se transita por essas normas de feminilidades e masculinidades que a moda e o vestuário constituem? Já que ser homem demanda também um trabalho, um processo pedagógico.

Atualmente, nem estranhamos mais quando vemos as mulheres de calça comprida; no entanto, não ocorre o mesmo quando homens usam saias ou pintam as unhas. As interdições referentes à moda estão tão enraizadas que dificilmente são questionadas. De acordo com José Dutra:

Movimento, Porto Alegre, v.13, n. 01, p.93-117, janeiro/abril de 2007. 


\begin{abstract}
Há tantos anos associada à futilidade e aos caprichos "próprios das mulheres" ou ainda às "frescuras" e aos "afetamentos" próprios das "bichas", é "natural" que a moda permaneça, nas representações coletivas, sendo uma técnica dispensável e não recomendável ao modelo de masculinidade que vigora. No entanto, não há nada que impeça o desenvolvimento de modelos alternativos de masculinidade, orientados por novas e diferentes concepções do que é ser homem (DUTRA, 2002, p.367).
\end{abstract}

No que tange à moda feminina, esta vem, desde a era vitoriana, alternando-se em ciclos, mas mantendo a ênfase no princípio da sedução. Para os homens de negócios ou que ocupam cargos públicos, a moda fica cada vez mais discreta e ascética, tornandoos mais invisíveis e distintos, sendo a distinção uma ferramenta fundamental de prestígio e ascensão social (SOUZA, 2001). No entanto, entre os homens jovens que são citados pelas participantes da pesquisa, a tendência é completamente outra, muito mais próxima dos movimentos culturais/musicais que assumem posições mais andróginas, rebelando-se com normas de austeridade do vestuário masculino.

Talvez a grande ruptura com os modelos padronizados e ascéticos do vestuário masculino tenha ocorrido a partir da década de 60 do século passado, no bojo das lutas empreendidas pelos movimentos de contestação na Europa e em boa parte do mundo ocidental. Na esteira desses movimentos de contestação, emerge 0 movimento da contra-cultura, que utiliza as questões urbanas para desafiar o status quo da cultura de elite. A alta costura e a moda prête-à-porté é alvo desse movimento, no qual as roupas de rua ou de inspiração étnica representam a ruptura com os modelos conservadores. Ao longo dos anos, a indústria da moda e do vestuário masculino vem realizando composições entre o estilo mais austero e o mais casual

Já a década de 1980 caracteriza-se como um tempo em que as grandes lutas contestatórias não têm mais lugar. Sendo assim,

Movimento, Porto Alegre, v.13, n. 01, p.93-117, janeiro/abril de 2007. 


\section{Ensaios}

a conjunção juventude/rebeldia, de lutas contra as grandes opressões, passa para protestos localizados em novos grupos. Surgem então espaços para uma "multiplicação de tribos", como punk, rock e heavy, ligadas, na maioria das vezes, aos movimentos da música pop.

Esse processo de tribalização da juventude não tem cessado até os dias de hoje, com o surgimento de novas e renovadas tribos, como as de surfes, clubbers, raps, góticos e pagodeiros, ainda que com novas configurações e arranjos de força que instituem rupturas e tensões na construção e expressão das referências culturais dos jovens. Essa tribalização articula-se à participação no consumo de moda e do lazer oferecido pela indústria do entretenimento. Uma das características das novas tribos urbanas é o trânsito de jovens entre elas - sem necessariamente se apropriarem de seus códigos os/as jovens apenas utilizam-se de alguns elementos estéticos de cada tribo. Uma tribo urbana é uma espécie de pacote de gosto musical, ídolos, roupas e acessórios, ao mesmo tempo em que pode ser simplesmente a expressão momentânea de preferência por uma moda ou por um artista pop.

Nesse contexto, os/as jovens encontram na mídia, no mundo do show business e no mercado de consumo a inspiração necessária para se expressarem, seja nos modos de vestir, seja na gestualidade que exibem. Assim, parece que as unhas pintadas de preto, a que uma das jovens havia se referido, conformam-se a diferentes tribos de inspiração musical no que se refere a adereços (crucifixos, piercings, correntes) e maquiagens (rímel e sombra) difundidos nos mercados de moda alternativos, como o "Mercado Mundo Mix"3 (MMM). A cor preta, nesses espaços, passa a significar rebeldia e contestação, ao mesmo tempo em que aponta para a possibilidade de múltiplas combinações.

A suposta novidade seria a de que homens aderissem a esses artifícios para intervir na aparência. Segundo Dutra, os diferentes

3 "O MMM pode ser considerado um parque fashion cultural onde se encontram roupas, cabeleireiros, maquiagens, acessórios, CDs, bodypiercing e uma rádio que toca durante todo o evento" (DUTRA, 2002, p.382).

Movimento, Porto Alegre, v.13, n. 01, p.93-117, janeiro/abril de 2007. 
indivíduos aderem às modas porque "[...] querem extrair satisfação, enviar mensagens novas, [...] se sentir contemporâneos, atualizados, ou mesmo à frente de seu tempo, querem se singularizar, sem correr o risco de parecerem ridículos" (DUTRA, 2002, p.405). O autor segue afirmando que, por mais paradoxal que pareça, é inegável o desejo de pertencimento, de ser diferente e, ao mesmo tempo, ser aceito pelo grupo.

Recuperando as questões de gênero, quando alguns jovens homens pintam as unhas na escola, os ideais de masculinidade heterossexual usuais sofrem um abalo nas observações das garotas e dos garotos, na medida em que o apreço e a observância das orientações da moda, tradicionalmente, pertencem à esfera feminina. Quando os homens demonstram seu interesse pela moda de maneira não tão discreta, parece ocorrer um tensionamento que constrange a ousadia, atribuindo-lhes significações de "frescura" ou traços de efeminização.

Os mercados alternativos, como o MMM, nasceram ligados ao movimento GLS (gays, lésbicas e simpatizantes), portanto, com a bandeira política da diversidade. No entanto, o público consumidor desses mercados ampliou-se muito, permitindo que outros segmentos da população, não necessariamente ligados ao GLS, aderissem à moda e aos estilos não-convencionais. Os/as homossexuais e os/as bissexuais têm produzido rompimentos e antecipado mudanças estéticas e comerciais importantes no que se refere à moda, de certa forma, rompendo fronteiras e tornando mais ambíguas as posições de polaridade de gênero e reduzindo as diferenças no vestuário masculino e feminino. Cabe afirmar que há muitos e múltiplos sentidos em "ser homem"; portanto, os homens, mesmo os mais novos, têm podido vivenciar outras possibilidades de masculinidade, ainda que comedidas e constantemente vigiadas. Nesse contexto de multiplicação das masculinidades, um exemplo que já ganhou notoriedade foi o termo "metrossexual". O jornalista inglês que o inventou, Mark Simpson, explica o que isso significa:

Metrossexual é o jovem que vive numa metrópole porque ali estão as melhores lojas, restaurantes,

Movimento, Porto Alegre, v.13, n. 01, p.93-117, janeiro/abril de 2007. 
academias de ginásticas e cabeleireiros. Ele é consumista, mas a sua preferência sexual é irrelevante, porque o objeto de amor e prazer do metrossexual é ele mesmo (Rede Globo de Televisão 14/05/2004).

O símbolo do homem metrossexual é mesmo o jogador de futebol David Beckham, que não só usa maquiagem como faz as sobrancelhas. Em um vídeo realizado pela artista britânica Sam Wood Taylor, Beckham aparece dormindo em um quarto de hotel em Madri, depois de um jogo de futebol. Nas orelhas do jogador, brincos de brilhantes, e, nas unhas, esmalte cintilante.

\section{CONSIDERAÇÕES FINAIS}

Meu interesse nessa discussão não é o de realizar reflexões profundas sobre a sexualidade masculina, mas indicar o caráter agudo da recomposição pelas quais as categorias relacionadas às identidades sexuais estão passando. Fernando Seffner (2003, p.12) também aponta para isso ao dizer que a nomeação de práticas sexuais, a produção de "sujeitos sexuais [...] é um processo que opera de modo constante na sociedade, e no qual cada um de nós pode funcionar ora como sujeito, ora como objeto".

Seria impensável, até pouco tempo atrás, que homens públicos, como um atleta famoso (ainda mais no contexto de um esporte como o futebol, que é símbolo de virilidade), se disponha a ocuparse, com tanto empenho, de cuidados estéticos tradicionalmente femininos como a maquiagem. Mesmo que, no caso desse jogador de futebol e "estrela galáctica"4 que é David Beckham, a mídia insista em afirmar que, apesar dos pesares, ele segue sendo "macho na cama".

Referindo-se, pois, aos garotos, as jovens participantes discutiram o que entendiam como masculinidades aceitáveis:

${ }^{4}$ É o apelido com que os principais jogadores do Real Madri como Ronaldinho, Zidane e Roberto Carlos são chamados, tanto pelos altos salários, quanto pela penetração que estes alcançam na mídia.

Movimento, Porto Alegre, v.13, n. 01, p.93-117, janeiro/abril de 2007. 
Flávia: Eu gosto, eu acho bonitinho! Não precisa ficar com aquelas unhas todas podres. Não, ele não vai deixar de ser homem por isso, sabes? Isso é uma coisa conhecida como sendo da mulher... E eu acho que tem muito preconceito em relação ao homem se cuidar, até no cabelo... geral, sabe. Eu acho que tem muito preconceito, por mais que tenha evoluído o mundo. Acho que tem muito preconceito ainda sobre isso.

Denise: Cortar, tirar a cutícula, tudo bem, só não pintar de esmalte!

Suzana: De repente, passar uma base, eu acho que isso também é sinal de higiene.

Kátia: Não é que eu me importe, mas acho que é uma coisa que não combina muito, até porque é uma coisa que geralmente é da mulher.

Com relação às discussões acima, as jovens dividem-se entre as que apóiam amplamente, as que apóiam com certas reservas e as que não apóiam a absorção, pelos meninos, de hábitos convencionalmente tidos como femininos. Chama a atenção a questão do preconceito levantada pela jovem. O tom era definidor do debate, como se por si só resolvesse a questão. O termo "preconceito" remete a uma idéia, conceito ou opinião formados antecipadamente. Cabe lembrar aqui um artigo de Rosângela Soares e Rosimeri Aquino (2003), em que as autoras discutem, entre outras coisas, o programa especial da MTV chamado "Fica Comigo Gay". Segundo elas, nos intervalos do programa, eram veiculadas vinhetas sobre temas relacionados a preconceito. Em uma dessas vinhetas, um texto dizia que "o pior dos preconceitos é ter preconceito" (SOARES; AQUINO, 2003, p.141). O preconceito, como algo politicamente errado, está ligado à idéia de assumir uma posição de forma apressada, ou melhor, ser intolerante.

A questão da tolerância vem sendo discutida e problematizada por grupos minoritários, principalmente os grupos das vertentes multiculturalistas, que estão empenhados em obter reconhecimento das suas formas culturais e em ver-se representados na cultura

Movimento, Porto Alegre, v.13, n. 01, p.93-117, janeiro/abril de 2007. 


\section{Ensaios}

nacional. A base deste debate está em destacar a diversidade das formas culturais do mundo contemporâneo. A principal crítica ao discurso da tolerância tem a ver com um a priori de que existe uma posição hierarquicamente superior, ou seja, uma certa superioridade que aceita ou tolera o outro e que seria igualada por sua suposta essência humana, sendo, nessa medida, que se tem o "[...] apelo para o respeito, a tolerância e a convivência pacífica entre as culturas" (SILVA, 2000, p.85).

Quando as jovens participantes utilizam-se de um discurso "politicamente correto" com relação a ter ou não preconceito, operam de modo a posicionar o garoto ou os garotos que pintam as unhas, por exemplo, próximos da norma. A mesma jovem que, na discussão, trouxe o argumento do preconceito disse depois que seu namorado também passa esmalte. Com isso, quero dizer que há uma tentativa de reafirmar a heterossexualidade dos garotos na medida em que a heterossexualidade feminina e masculina seria, para muitos dos discursos que circulam na cultura, a única forma sadia e normal de viver a sexualidade (LOURO, 2003).

Aceitando que os meninos demonstrem certos cuidados, como passar uma base, mas restringindo esse hábito a uma questão de higiene, as garotas podem estar apontando para a idéia de que unhas coloridas poderiam significar uma desestabilização da posição central ocupada pela masculinidade heterossexual. Segundo Louro: "A posição central é considerada a posição não problemática; todas as outras posições-de-sujeito estão de algum modo ligadas e subordinadas" (LOURO, 2003, p.44).

A norma vai sendo colocada em jogo pelas tecnologias de comunicação que estão apoiadas nos discursos científicos biomédicos. Deste modo, os cuidados com o corpo dependem ainda de um outro elemento que possa fazer os ajustes entre as possibilidades tecnológicas e a padronização de comportamentos exigida pelo mercado. Trata-se das relações de poder que realizam a passagem da norma ao risco. Posso exemplificar essa posição lembrando que muitas mulheres jovens se culpam pelo apetite, que funciona como um marcador social potente na medida em que pesa sobre a mulher gorda a ameaça de ela estar fora dos padrões da sociedade de Movimento, Porto Alegre, v.13, n. 01, p.93-117, janeiro/abril de 2007. 
consumo e o constrangimento sexual por estar fora do espectro do olhar social.

The care with the body as strategy of gender
citizens
Abstract: This paper is part of a Master's
Dissertation which discussed some ways young
women give meaning to, learn, grasp and
experience body care in contemporaneity. It is
inscribed in the fields of gender studies, in
approaches with a critical approximation to the post-
structuralist perspective put forward by Michel
Foucault. It uses the methodological approach of
discourse analysis to examine discussions carried
a public school. In the analyses resulting from this
corpus of investigation, we have focused on a
movement which allows for re-signifying gender
body in contemporaneity.
Keywords: Body Image. Gender identity.
Adolescent. Education, primary and secondary

El cuidado con el cuerpo como estrategia de sujetos generificados

Resumen: El presente artículo es parte de una disertación de maestría que investiga los modos como las jóvenes mujeres significan, aprenden e viven, en la contemporaneidad el cuidado de su cuerpo. La análisis se plantea en el campo de los estudios de género, en las corrientes próximas con la perspectiva pos-estructuralista de Michel Foucault. Se utiliza el instrumento de "análisis del discurso" para el examen de narrativas de estudiantes de una escuela publica. En este trabajo, el enfoque son los movimientos que permiten dar un novo significado a los cuerpos generificados de los tiempos contemporáneos.

Palabras clave: Imagen corporal. Identidad de género. Adolescente. Educación primaria y secundaria.

Movimento, Porto Alegre, v.13, n. 01, p.93-117, janeiro/abril de 2007. 


\section{REFERÊNCIAS}

ADELMAN, Miriam. Mulheres atletas: re-significações da corporalidade feminina. Revista dos Estudos Feministas, Florianópolis, v. 11, n. 2, p.445-465, jul/dez. 2003.

BRUMBERG, Joan. The body project: an intimate history of American girls. New York: Random House, 1997.

DUTRA, José Luis. "Onde você comprou esta roupa tem para homem?": A construção de masculinidades nos mercados alternativos de moda. In: GOLDEMBERG, A; RAMOS, A. Nú e Vestido: dez antropólogos revelam a cultura do corpo carioca. Rio de Janeiro: Record, 002. p.359 -412.

EWALD, François. Foucault a norma e o direito. Lisboa: Veja, 1993.

FOUCAULT, Michel. As palavras e as coisas: uma arqueologia das ciências humanas. São Paulo: Martins Fontes, 2002.

FRAGA, Alex. Evangelho do agito: uma forma de ativar o corpo e regular a vida. Porto Alegre: UFRGS/Faced, 2002. (Proposta de Tese)

GOELLNER, S.; NECKEL, J; LOURO, G. (Org.) Corpo, gênero e sexualidade: um debate contemporâneo na educação. Petrópolis: Vozes, 2003.

LOURO, Guacira. Currículo, gênero e sexualidade: o "normal", o "diferente" e o "excêntrico". In: LOURO, G.; NECKEL, J.; GOELLNER, S. (Org.) Corpo, Gênero e Sexualidade: um debate contemporâneo. Petrópolis: Vozes, 2003. p.41-52.

LOURO, Guacira. Gênero, Sexualidade e Educação: Uma perspectiva pós-estruturalista. Petrópolis: Vozes, 1997.

MEYER, Dagmar. Gênero e educação: teoria e política. In: LOURO, G.; NECKEL, J. Corpo, gênero e sexualidade: um debate contemporâneo na educação. Petrópolis: Vozes, 2003. p.9-27.

REDE GLOBO DE TELEVISÃO. Programa Globo Repórter [de 14 maio 2004]. Disponível em: <http://redeglobo6.globo.com/Globoreporter/html.> Acesso em: 12 ago. 2004.

SANT'ANNA, Denise. É possível realizar uma história do corpo. In: SOARES, C. Corpo e história. Campinas: Autores Associados, 2001. p.3-24.

SANTOS, Luis Henrique Sacchi dos Santos. Um olhar caleidoscópico sobre as representações culturais de corpo. 1998. 207 f Dissertação (Mestrado) - Faculdade de Educação, Curso de Pós-Graduação em Educação, UFRGS, Porto Alegre, 1998.

Movimento, Porto Alegre, v.13, n. 01, p.93-117, janeiro/abril de 2007. 
SILVA, Ana M. Corpo, ciência e mercado: reflexões acerca da gestação de um novo arquétipo da felicidade. Campinas: Autores Associados, 2001.

SILVA, Tomás Tadeu. (org). Nunca Fomos Humanos: nos rastros dos sujeitos. Belo Horizonte: Autêntica, 2001.

SILVA, Tomás Tadeu. Documentos de Identidade: uma introdução às teorias do currículo. Belo Horizonte: Autêntica, 1999.

SOUZA, Nádia Geiza Silveira de. Que corpo é esse? O corpo na família, mídia, escola, saúde... 2001. 168 f. Tese (Doutorado) - Instituto de Ciências Básicas da Saúde, Curso de Pós Graduação em Ciências Biológicas: Bioquímica, UFRGS, Porto Alegre, 2001

STEINBERG, Shirley. Kindercultura: a construção da infância pelas grandes corporações. In: SILVA, Luis Heron; AZEVEDO, José; SANTOS, Edmilson (Org.). Identidade social e a construção do conhecimento. Porto Alegre: SMED, 1997. p.98-145. 